\title{
DECREASED NEURON LOSS AND MEMORY DYSFUNCTION IN PILOCARPINE-TREATED RATS PRE-EXPOSED TO HYPOXIA
}

\author{
RAQUEL ARAUJO DO VAL-DA SILVA, ${ }^{a}$ \\ JOSÉ EDUARDO PEIXOTO-SANTOS, ${ }^{a}$ \\ RENATA CALDO SCANDIUZZI, \\ PRISCILA ALVES BALISTA, ${ }^{a}$ MIRIAN BASSI, \\ MOGENS LESNER GLASS, \\ RODRIGO NEVES ROMCY-PEREIRA, ${ }^{d}$ \\ ORFA YINETH GALVIS-ALONSO ${ }^{\circ}$ AND \\ JOÃO PEREIRA LEITE ${ }^{\text {a* }}$ \\ ${ }^{a}$ Department of Neuroscience and Behavioral Sciences, Ribeirão \\ Preto School of Medicine, University of São Paulo, Ribeiãro Preto \\ 14049-900, Brazil \\ ${ }^{\mathrm{b}}$ Department of Physiology, Ribeiãro Preto School of \\ Medicine, University of São Paulo, Ribeirao Preto 14049-900, Brazil \\ ${ }^{\mathrm{c}}$ Department of Physiology and Pathology, Araraquara School \\ of Dentistry, São Paulo State University, Brazil \\ ${ }^{\mathrm{d}}$ Brain Institute, Federal University of Rio Grande do Norte, \\ Natal 59056-450, Brazil \\ e Department of Molecular Biology, São José do Rio Preto \\ Medical School, São José do Rio Preto 15090-000, Brazil
}

\begin{abstract}
Preconditioning can induce a cascade of cellular events leading to neuroprotection against subsequent brain insults. In this study, we investigated the chronic effects of hypoxic preconditioning on spontaneous recurrent seizures (SRS), neuronal death, and spatial memory performance in rats subjected to pilocarpine (Pilo)-induced status epilepticus (SE). Rats underwent a short hypoxic episode $\mathbf{( 7 \%}$ $\mathrm{O}_{2}+93 \% \mathrm{~N}_{2} ; 30 \mathrm{~min}$ on two consecutive days) preceding a 4-h SE (HSE group). Control groups were rats submitted to SE only (SE), rats subjected to hypoxia only $(H)$ or normoxia-saline (C). Animals were monitored for the occurrence of SRS, and spatial memory performance was evaluated in the radial-arm maze. Hippocampal sections were analyzed for cell death and mossy fiber sprouting at 1 or 60 days after SE. Compared to SE group, HSE had increased SE latency, reduced number of rats with SRS, reduced mossy fiber sprouting at 60 days, and reduced cell death in the hilus and the CA3 region 1 and 60 days after SE. Additionally, HSE rats had better spatial memory performance than SE rats. Our findings indicated that short hypoxic preconditioning preceding SE promotes long-lasting protective
\end{abstract}

*Corresponding author. Address: University of São Paulo, Ribeirão Preto School of Medicine - FMRP, Dept. of Neuroscience and Behavioral Sciences, Av. Bandeirantes, 3900, Ribeirão Preto, SP 14049-900, Brazil.

E-mail address: jpleite@fmrp.usp.br (J. P. Leite).

Abbreviations: ANOVA, analysis of variance; DG, dentate gyrus; GABA, gamma-aminobutyric acid; KA, kainic acid/kainate; Li, lithium chloride; MTLE, mesial temporal lobe epilepsy; Pilo, pilocarpine; RMANOVA, two-way analysis of variance for repeated measures; SE, status epilepticus; SEM, standard error of mean; SRS, spontaneous recurrent seizures; $\chi^{2}$, Chi-square.

http://dx.doi.org/10.1016/j.neuroscience.2016.06.047

0306-4522/@ 2016 IBRO. Published by Elsevier Ltd. All rights reserved. effects on neuron survival and spatial memory. (C) 2016 IBRO. Published by Elsevier Ltd. All rights reserved.

Key words: temporal lobe epilepsy, hypoxic preconditioning, pilocarpine-induced status epilepticus, neuronal death, mossy fiber sprouting, memory deficit.

\section{INTRODUCTION}

Mesial temporal lobe epilepsy (MTLE) is characterized by focal seizures originating in the temporal lobe (Berg et al., 2010) A common neuropathological feature of MTLE is hippocampal sclerosis, characterized by neuron loss in selective hippocampal subfields, widespread hippocampal gliosis, and aberrant mossy fiber sprouting in the molecular layer of the dentate gyrus (DG) (Sutula et al., 1989; Babb et al., 1991; McNamara, 1994; Mathern et al., 1996; Kandratavicius et al., 2015; Peixoto-Santos et al., 2015).

In the chronic phase of pilocarpine (Pilo) rodent model, spontaneous recurrent seizures (SRS) and behavioral disturbances are observed, and the neuropathological changes closely reproduce those found in MTLE (Turski et al., 1983; Jope et al., 1986; Clifford et al., 1987; Leite et al., 1990; Mello et al., 1993; Wasterlain et al., 1993; Leite et al., 2002; Rao et al., 2006; Kandratavicius et al., 2014a). Clinical and experimental evidence indicates a positive correlation between SRS frequency and neuron loss (Lowenstein, 1996; Ben-Ari and Cossart, 2000). Hence, the search for neuroprotective treatments has become a focus of interest in the study of MTLE due to their possible implications for the prevention of SRS and neuropathological changes (Curia et al., 2014).

Experimental studies have evaluated the neuroprotective effects of preconditioning over seizures and neuronal loss (Kitagawa et al., 1990; Bortolotto et al., 1991; Sasahira et al., 1995; Najm et al., 1998; Andre et al., 2000; Zhang et al., 2002; Boeck et al., 2004; Andre et al., 2007; de Araujo Herculano et al., 2011; Xue et al., 2011). Most preconditioning studies used a subthreshold stimulus, followed by the same stimulus in a status epilepticus (SE)-inducing dosage. Examples of this preconditioning approach include subthreshold kainic acid (KA) injection or a short KA-induced seizure previous to KA-induced SE (Najm et al., 1998; Zhang et al., 2002), nonconvulsive NMDA treatment before quinolinic acid-induced SE (Boeck 
et al., 2004; de Araujo et al., 2011) and one episode of bicuculline-induced seizure prior to a later bicucullineinduced seizure episode (Sasahira et al., 1995). Other studies used a preconditioning stimulus different from the SE-inducing stimulus, taking advantage of the cross-tolerance phenomenon, where an insult can induce tolerance from a later insult of different nature (Kirino, 2002). Examples include amygdala kindling or maximal electroshock prior to Pilo-induced SE (Andre et al., 2000; Andre et al., 2007), diazoxide prior to Pilo-SE (Xue et al., 2011), and brief ischemia prior to electrical hippocampal kindling (Bortolotto et al., 1991).

Hypoxia is an important inducer of cross-tolerance for SE (Kirino, 2002), and occurs during seizures, as indicated by expression of hypoxia-inducible factor $1 \alpha$ (HIF$1 \alpha)$ and the accumulation of pimonidazole in interneurons shortly after SE and SRS, but not during the silent period (Gualtieri et al., 2013). Further experimental studies have shown magnetic resonance (MR) detectable cortical hypoperfusion, with flattening of blood vessels, changes in vascular permeability, and signals of neuronal degeneration detected in the histological examination (Fabene et al., 2007), as well as signals of hippocampal ischemia, with higher T2 signal, hypointense apparent diffusion coefficient, increased vessels diameters, microhemorrhages and necrosis after Pilo-SE (Lucchi et al., 2015). Human studies corroborate the occurrence of hypoxia associated with seizures, showing expression of HIF-1 $\alpha$ in the epileptogenic focus (Gualtieri et al., 2013) and reduction of oxygen saturation during seizures, especially in seizures whose focus is the temporal lobe and that spread contralaterally (Bateman et al., 2008). Despite the degenerative effects of long hypoxic events, hypoxia preconditioning reduces seizure susceptibility, seizure severity, and acute hippocampal neuron loss (Pohle and Rauca, 1994; Emerson et al., 1999; Rauca et al., 2000; Rubaj et al., 2000; Chang et al., 2005). However, the long-term effects of hypoxic preconditioning on the chronic phase neuron loss and memory are not known. Therefore, our aim was to examine the effects of two short-term controlled hypoxic preconditioning episodes on acute ictal SE behavior, chronic SRS, spatial memory performance and neuropathology in adult rats submitted to Li-Pilo-induced SE.

\section{EXPERIMENTAL PROCEDURES}

\section{Animals}

Adult male Wistar rats $(200-250 \mathrm{~g})$, provided by University of São Paulo, were used. Animals were maintained on a 12-12-h light/dark cycle, with lights-on at 7:00 A.M., in a temperature-controlled room at 24 $\pm 1^{\circ} \mathrm{C}$, and with free access to food and water. All procedures were approved by the Ethics Commission for Animal Experimentation of the University of São Paulo (Process \#092/2005) and were in agreement with the guidelines established by the Brazilian College for Animal Experimentation (COBEA) and affiliated with the International Council for Laboratory Animal Science (ICLAS). All efforts were made to minimize the number of animals used and their suffering.

\section{Experimental paradigm}

Rats were subdivided into four experimental groups: control (C, $n=10)$, comprised by rats not submitted to preconditioning or SE; hypoxia only $(\mathrm{H}, n=10)$, rats submitted to hypoxia preconditioning followed by saline treatment; SE only (SE, $n=10$ ), non-preconditioned animals submitted to Pilo-induced SE; and hypoxia + SE (HSE, $n=10$ ), preconditioned rats submitted to Pilo-induced SE (Table 1). On days 1 and 2, rats were submitted to $30 \mathrm{~min}$ normoxia treatment ( $C$ and SE groups) or 30 min hypoxia preconditioning ( $\mathrm{H}$ and $\mathrm{HSE}$ groups). At the end of day 2 , all rats were injected with lithium chloride $(\mathrm{Li})$, to reduce the status inducing Pilo dosage. On day 3, rats were submitted to saline injection ( $\mathrm{C}$ and $\mathrm{H}$ groups) or Pilo-induced SE (HSE and SE groups). Sodium thiopental was used to abort SE after four hours (HSE and SE groups). On day 4 (24 h after SE abortion) five rats from each group were euthanized and their brains processed for paraffin embedding ( 1 day groups). From day 8 (i.e., five days after Pilo-induced SE) until day 60 , the remaining rats from SE and HSE groups were monitored individually $8 \mathrm{~h}$ per day for the evaluation of SRS. On day 60, the remaining twenty rats were euthanized and their brains processed for paraffin embedding (60 days groups). A different set of rats from C, HSE, and SE groups $(n=6$ per group) was produced in the same way described above exclusively for the spatial memory test. These animals were not recorded or had their brains processed for paraffin embedding.

\section{Hypoxia preconditioning}

In order to define the appropriate hypoxia paradigm, we realize preliminary experiments to test the following hypoxia variables: (1) concentration of oxygen $\left(5 \% \mathrm{O}_{2}\right.$ with $95 \% \mathrm{~N}_{2}, 6 \% \mathrm{O}_{2}$ with $94 \% \mathrm{~N}_{2}, 7 \% \mathrm{O}_{2}$ with $93 \% \mathrm{~N}_{2}$, or $8 \% \mathrm{O}_{2}$ with $92 \% \mathrm{~N}_{2}$ ); (2) duration (10, 20 and $30 \mathrm{~min}$ ); (3) number of episodes ( 1 and 2). The interval between hypoxia episodes was maintained in 1 day. The criterion to choose our paradigm was when hypoxia by itself induced a stress response (reduced exploratory activity and hyperventilation) without leading to the death of animals or neuropathological evidence of neuron degeneration seven days after hypoxia episodes using Fluoro-Jade B histochemistry. All low oxygen mixtures tested lead to reduced exploratory activity and hyperventilation. The $5 \% \mathrm{O}_{2}+95 \% \mathrm{~N}_{2}$ mixture lead to the death of all rats within $10 \mathrm{~min}$, whereas the remaining mixtures promoted no death within $30 \mathrm{~min}$. Fluoro-Jade B staining revealed severe neuronal degeneration in CA1 and CA3 of all rats submitted to two episodes of $30 \mathrm{~min}$ of the $6 \% \mathrm{O}_{2}+94 \% \mathrm{~N}_{2}$ mixture, whereas no neurons in degeneration were seen after two episodes of 30 min of the $7 \% \quad \mathrm{O}_{2}+93 \% \quad \mathrm{~N}_{2}$ mixture. The final hypoxia paradigm chosen was two sessions of hypoxia $\left(7 \% \mathrm{O}_{2}\right.$ with $93 \% \mathrm{~N}_{2}$ ) of $30 \mathrm{~min}$ each, in consecutive days.

Our hypoxia paradigm consisted of two steps: acclimation and hypoxia. First, animals from HSE or $\mathrm{H}$ groups were subjected to acclimation using a whole-body plethysmography, homemade chamber 
Table 1. Experimental paradigm

\begin{tabular}{|c|c|c|c|c|}
\hline & First day & Second day & Third day & Survival time \\
\hline$C$ & Normoxia & $\begin{array}{l}\text { Normoxia } \\
\rightarrow \text { Saline }\end{array}$ & Saline & $1 \mathrm{~d}$ or $60 \mathrm{~d}$ \\
\hline $\mathrm{H}$ & Hypoxia $=30 \mathrm{~min}$ & $\begin{array}{l}\text { Hypoxia }=30 \mathrm{~min} \\
\rightarrow \text { Saline }\end{array}$ & Saline & $1 \mathrm{~d}$ or $60 \mathrm{~d}$ \\
\hline SE & Normoxia & $\begin{array}{l}\text { Normoxia } \\
\rightarrow \text { Lithium chloride }\end{array}$ & Pilo $\rightarrow$ SE $=4 \mathrm{~h}$ & $1 \mathrm{~d}$ or $60 \mathrm{~d}$ \\
\hline HSE & Hypoxia $=30 \mathrm{~min}$ & $\begin{array}{l}\text { Hypoxia }=30 \mathrm{~min} \\
\rightarrow \text { Lithium chloride }\end{array}$ & Pilo $\rightarrow$ SE $=4 \mathrm{~h}$ & $1 \mathrm{~d}$ or $60 \mathrm{~d}$ \\
\hline
\end{tabular}

Animal groups: control (C), hypoxia (H), status epilepticus (SE) and hypoxia followed by status epilepticus (HSE).

(transparent acrylic box; $19 \times 19 \times 12 \mathrm{~cm}$ ), as previously described (Bassi et al., 2015) under a normoxic gas mixture $\left(21 \% \mathrm{O}_{2} ; 79 \% \mathrm{~N}_{2}\right)$ with airflow of $1000 \mathrm{ml} / \mathrm{min}$ for 10-20 min in an internal constant volume. Following acclimation, all animals were subjected to a hypoxic gas mixture $\left(7 \%\right.$ of $\mathrm{O}_{2}$ and $93 \%$ of $\left.\mathrm{N}_{2}\right)$ under the same airflow for $30 \mathrm{~min}$. Animals from the non-preconditioned groups ( $C$ and SE) were also maintained in the plethysmography chamber for the same time as hypoxic preconditioned groups but were only submitted to the normoxic gas mixture $\left(21 \% \mathrm{O}_{2} ; 79 \% \mathrm{~N}_{2}\right)$ throughout the entire experiment (i.e., $40-50 \mathrm{~min}$ ). The hypoxic and normoxic mixtures were administered under controlled conditions $\left(25^{\circ} \pm 1^{\circ} \mathrm{C}\right.$ and $50 \%$ humidity), during the light cycle at morning for all experimental procedures. Both breathing frequency and pulmonary ventilation were measured to evaluate the level of hypoxia. Breathing frequency was measured during the last minute of each treatment with the interruption of airflow for one minute. The system was calibrated by the injection of $0.3 \mathrm{ml}$ of air 3-4 times before recording each animal. Pulmonary ventilation was calculated based on alterations between inspired (at $25^{\circ} \mathrm{C}$ ) and expired air volume (at $37^{\circ} \mathrm{C}$ ) detected by a transducer (Valadyne Engineering Corp CA, USA) connected to the plethysmography chamber and subsequently transmitted to a pre-amplifier (Valadyne Engineering Corp CA, USA) connected to a data recording system (National Instruments, USA). Recorded data were stored in a microcomputer for offline analysis.

Pulmonary ventilation values were calculated according to a plethysmography method for small animals (Malan, 1973). Breathing frequency $\left(f_{R}\right.$, breaths/ $\mathrm{min}$ ), inspiratory and expiratory duration, and peak airflow rates were automatically calculated from the airflow traces. The software system provided a breath-perbreath display of minute breathing frequency $\left(f_{R}\right.$, in breaths $\mathrm{min}^{-1}$ ) throughout each experiment, wave variation and calibration. Ventilation $\left(V_{\mathrm{E}}\right.$, in $\left.\mathrm{ml} \mathrm{kg}^{-1} \mathrm{~min}^{-1}\right)$ and tidal volume $\left(V_{\mathrm{T}}\right.$, in $\left.\mathrm{ml} \mathrm{kg}^{-1}\right)$ were calculated according to previously published methods (Bassi et al., 2015). For these analyses, we used Acknowledge 3.5 (Biopac System Inc.). Additionally, to assure that the hyperventilation seen in hypoxic animals hadn't compensated for the low oxygen present in the air, we calculated the amount of oxygen inhaled (in $\mathrm{ml} \mathrm{min}^{-1}$ ), with the following formula: Inhaled oxygen $=$ Ventilation $\times$ rat weight (in $\mathrm{kg}) \times$ oxygen concentration $(0.21$ for normoxia and 0.07 for hypoxia).

\section{Li-Pilo model of SE}

Animals from the HSE and SE groups were pretreated with $\mathrm{Li}(127.17 \mathrm{mg} / \mathrm{kg}$, i.p.; Sigma, IL, USA) $20 \mathrm{~h}$ before Pilo injection (30 mg/kg, s.c.; Sigma, IL, USA). At SE onset, animals also received an injection of methylscopolamine (1 mg/kg s.c., Sigma, IL, USA), to reduce the peripheral side effects of Pilo. Briefly, motor seizures were classified according to Racine's scale (Racine, 1972) in five characteristic stages: (1) mouth and facial movements, (2) head nodding, (3) forelimb clonus, (4) rearing, (5) rearing and falling. Four hours after the initial observation of head myoclonic movements (Racine stage 2; SE onset), rats were treated with sodium thiopental $(20 \mathrm{mg} / \mathrm{kg}$, i.p.; Abbott, SP, Brazil). Finally, all animals were daily monitored to assure food and water intake and proper recovery. The behavior analyses were done quantifying: (1) during SE: the latency to SE (minutes) and the maximum Racine's score obtained during the $4 \mathrm{~h}$ of SE; (2) during SRS: latency (days), the severity (total of Racine's score obtained during 60 days), number, and duration (seconds) of SRS episodes.

\section{Spatial memory tests on the radial arm maze}

For the spatial memory test, a separate set of rats from $C$, $\mathrm{SE}$, and HSE groups were produced ( $n=6$ per group), as mentioned in experimental paradigm section. After Pilo (HSE and SE) or saline (C) injections (day 3), these rats were housed in pairs (with other animals from the same group), and daily handled for 13 days to allow recovery from SE. From day 16 until the end of the radial maze experiments (i.e., on day 60), animals were placed under mild food deprivation state. The animals were maintained at $85 \%$ of their "ad libitum" weight (Touzani et al., 2007), which created an incentive for foraging on the maze without affecting their health. Before the start of training sessions in the radial arm maze (Insight, SP, Brazil), the rats were habituated to the maze over three days (once per day). On the first day (day 43), they were habituated to the maze without food pellets; on the second day (day 44), they were habituated to food pellets in the middle of each arm and next to the wells; on the third day (day 45), they were habituated to food pellets inside the wells, at the end of the arms. During these three days, the doors controlling the arms were regularly opened and closed providing progressive acquaintance of the rats to the doors movements and sounds. 
Each habituation session lasted $10 \mathrm{~min}$ and until all pellets were obtained. The spatial memory test used was the full-baited maze procedure, where rats had to learn to visit each arm only once within a trial (Olton, 1976). Rats were given one trial per session in the morning over 15 days (from day 46 until day 60). Animals that did not visit arms were excluded. A trial started with the animal placed in the central area with all the doors closed and all arms baited. After a 15-s delay, all eight doors were simultaneously opened, and the animals were free to choose the arms. Once the rat entered an arm, all the remaining doors were closed, and the animal was allowed to eat the food pellet and return to the central arena. At this time, the chosen arm door was closed. After a 5-s interval confinement in the central arena, all doors were re-opened, and the same procedure was performed. The trial was considered completed when one of the following conditions was reached: the animal visited all eight baited arms, or the trial reached $10 \mathrm{~min}$. Between each animal trial, the maze was cleaned with a wet paper towel to minimize the olfactory intra-maze cues. The maze was rotated $45^{\circ}$ before every daily session. The testing room was enriched with several salient visual cues on the walls consisting of vertical stripes, red and blue squares and triangles. Test performances were evaluated by calculating (1) the number of reference memory errors (2) the time to obtain all pellets. An error was defined as the number of entries in previously visited arms.

\section{Perfusion and histochemistry}

At the end of the experiments (day 4 for the acute treatment groups and day 60 for the chronic treatment groups), rats were anesthetized with sodium thiopental (40 mg/kg, i.p.; Abbott, SP, Brazil) and transcardially perfused with an infusion of $0.9 \%$ saline $(100 \mathrm{ml})$, followed by $0.1 \%$ sodium sulfide nonahydrate (SigmaAldrich, MO, USA) in $0.9 \%$ saline $(150 \mathrm{ml})$ and $4 \%$ phosphate-buffered paraformaldehyde (150 ml; SigmaAldrich MO, USA). The brains were fixed for another four hours in the same fixative solution, immersed in alcohol $50 \%$ to $100 \%$ and xylene, and then, included in paraffin at $58{ }^{\circ} \mathrm{C}$. Brains were coronally sectioned $(8-\mu \mathrm{m}$ sections) in a sliding microtome from $-3.30 \mathrm{~mm}$ to $-3.60 \mathrm{~mm}$ posterior to bregma, according to the Paxinos and Watson atlas (Paxinos, 1986). Sections were stained with Nissl and neo-Timm staining to quantify total cell number and mossy fiber sprouting, respectively. The histological analysis was done in five subfields of the hippocampal formation (DG, hilus, CA1, CA2, CA3) of all animal groups, following Lorente de Nó's (Lorente de Nó, 1934) hippocampal subdivision.

Quantitative assessment of Nissl-stained sections was conducted by visually counting morphologically defined neurons in three squares of $10,000 \mu \mathrm{m}^{2}$ in CA2 and the hilus and five squares of $10,000 \mu \mathrm{m}^{2}$ in CA3c, CA3b, $\mathrm{CA} 3 \mathrm{a}$, and $\mathrm{CA} 1$ in both hemispheres. Neuron density was then obtained according to Abercrombie's method (Abercombrie, 1946). Neuron density, as determined with Abercrombie method, is widely used in histopathological studies (Mathern et al., 1995a; Arthur-Farraj et al., 2012; Lee et al., 2012; Kandratavicius et al., 2013; Kandratavicius et al., 2014b), and gives similar results to stereological evaluation (Tramontin et al., 1998; Baquet et al., 2009). To examine the intensity of neo-Timm staining, we used a semi-quantitative scale for ranking mossy fiber gray intensity in the inner molecular layer of the DG (Tauck and Nadler, 1985). The degree of mossy fiber sprouting in the hippocampus of each rat was qualitatively compared, and examiners were blinded to experimental condition. Mossy fiber scores ranged from 0 (no staining) to 3 (intense staining) in the inner molecular layer of DG according to staining intensity. The neo-Timm analysis was done categorizing the number of animals for each group in scores ranged 0-1 (low scores) and 2-3 (high scores). Additionally, Fluoro-Jade B histochemistry, following published protocols (Schmued et al., 1997). was used during the standardization of the hypoxia protocol, to assure that neuron death was not an effect of the hypoxia pretreatment itself. No Fluoro-Jade B positive cells were seen in the hippocampal regions in both hemispheres after hypoxia procedure with $7 \% \mathrm{O}_{2}+93 \% \mathrm{~N}_{2}$ mixture (Fig. 1).
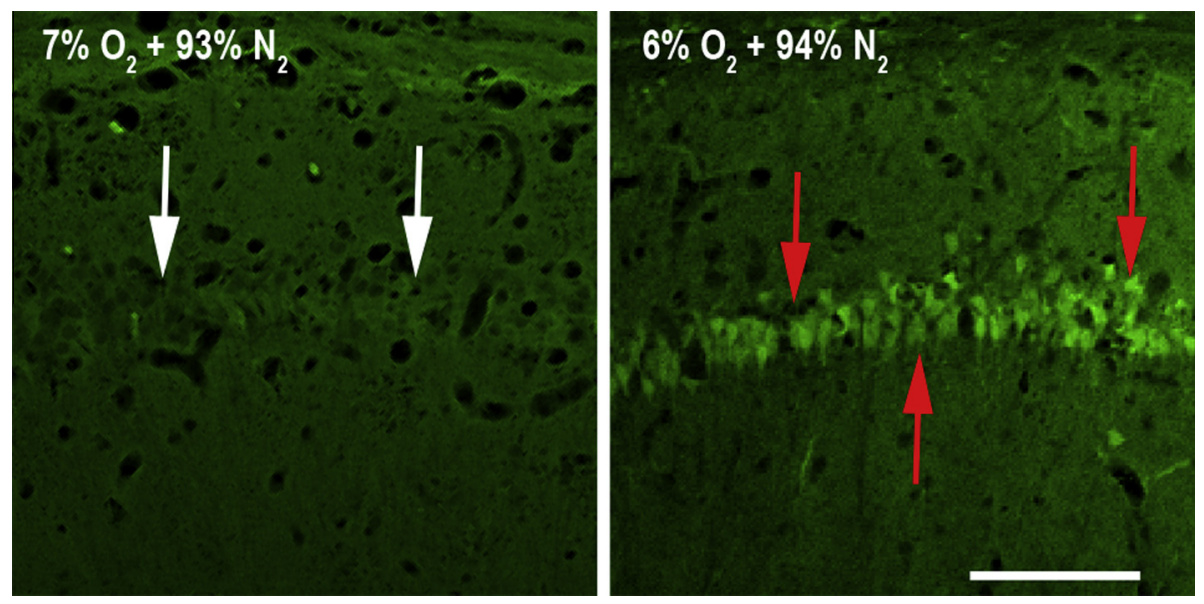

Fig. 1. Fluoro-Jade $B$ micrographs from the $\mathrm{CA} 1$ subfield of rats submitted to hypoxia preconditioning standardization. Whereas all pyramidal neurons of CA1 of rats submitted to $30 \mathrm{~min}$ of $6 \% \mathrm{O}_{2}+94 \% \mathrm{~N}_{2}$ hypoxic mixture were positive to Fluoro-Jade staining, no Fluoro-Jade positive neuron is seen in rats submitted to $7 \% \mathrm{O}_{2}+93 \% \mathrm{~N}_{2}$ mixture. Both rats underwent two episodes (in consecutive days) of 30 min hypoxic mixture. The bar in the right indicates $100 \mu \mathrm{m}$. 


\section{Data analysis}

All data was tested for normal distribution and homogeneity of variances. For variables that fulfilled both assumptions, statistical differences were determined using Student's $t$-test or analysis of variance (ANOVA) followed by Tukey's post hoc test. For nonparametric data, we used either Mann Whitney's or Kruskal Wallis's test followed by Dunn's test. Nominal scale data was analyzed using $\chi^{2}$-test or, if one of the categories compared had less than five observations, Fisher's exact test.

For the evaluation of spatial memory performance, the statistical analysis of group differences after 15 days training session was done using a mixed model two-way ANOVA for repeated measures (RM ANOVA). StudentNewman-Keuls post hoc test was used following RM ANOVA. Data were expressed as mean \pm SEM
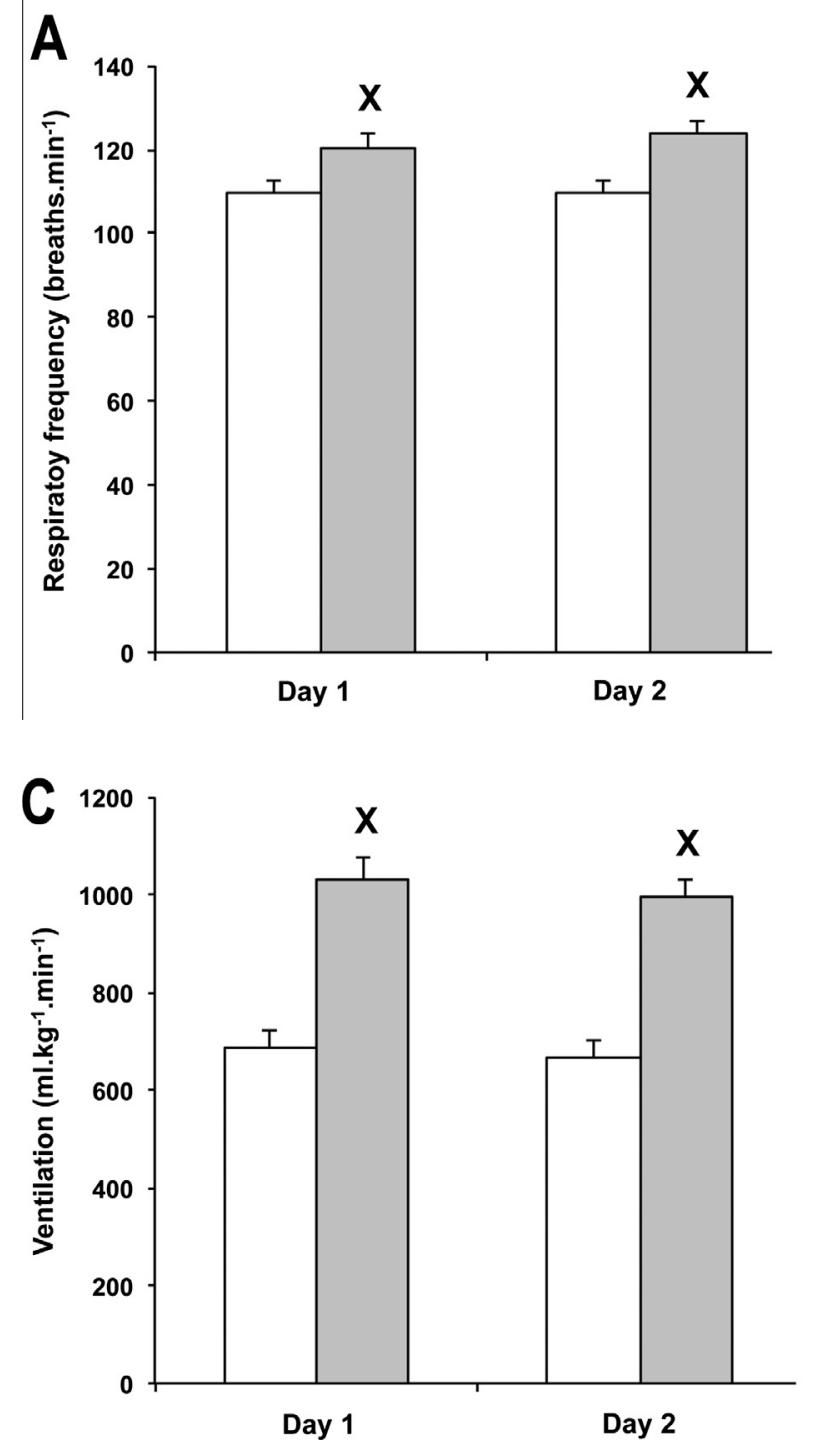

(standard error of the mean) and the significance level was set at $p<0.05$.

\section{RESULTS}

\section{Hypoxia and ventilation responses}

To assess the autonomic ventilation response of animals during hypoxia and to be able to correlate them to the levels of tissue damage due to SE, we measured the ventilation rate of animal in all four groups.

Immediately after hypoxia onset, animals showed hyperventilation and reduced exploratory activity. Both behaviors disappeared within minutes after the end of hypoxia. The animals subjected to hypoxia had higher ventilation rates (Fig. $2 \mathrm{C}$ ) than the animals subjected to normoxia, both in the first day $(1030 \pm 281$ $\mathrm{mL} \mathrm{kg}{ }^{-1} \min ^{-1} ; \quad 686 \pm 231 \mathrm{~mL} \mathrm{~kg}^{-1} \min ^{-1} ; \quad p \leqslant 0.001$,

Fig. 2. Respiratory frequency (A), tidal volume (B), ventilation rate (C), and inhaled oxygen volume (D) of rats submitted to 30 min of normoxic (21\% $\mathrm{O}_{2}$ and $\left.79 \% \mathrm{~N}_{2}\right)$ or hypoxic $\left(7 \% \mathrm{O}_{2}\right.$ and $\left.93 \% \mathrm{~N}_{2}\right)$ air mixtures in two consecutive days. Rats treated with hypoxic mixture had a higher respiratory frequency, higher tidal volume, higher ventilation rate, and lower inhaled oxygen volume than those submitted to a normoxic mixture in both days. The $(\times)$ indicate difference from the normoxic group. 
Mann-Whitney's test) and in the second day (994 \pm $233 \mathrm{~mL} \mathrm{~kg}^{-1} \mathrm{~min}^{-1} ; 667 \pm 219 \mathrm{~mL} \mathrm{~kg}^{-1} \min ^{-1} ; p \leqslant 0.001$, Student's $t$-test). The alteration in ventilation rates is associated with the elevation in frequency rates and tidal volume (Fig. 2A and B). Rats submitted to hypoxia inhaled half the amount of oxygen than those submitted to normoxic gas mixture (Normoxic $=34.06 \pm 1.79 \mathrm{ml}$ of $\mathrm{O}_{2}$ per minute in the first episode and $34.45 \pm 1.8 \mathrm{ml}$ of $\mathrm{O}_{2}$ per minute in the second episode; Hypoxic $=17.07$ $\pm 0.73 \mathrm{ml}$ of $\mathrm{O}_{2}$ per minute in the first episode and 17.15 $\pm 0.67 \mathrm{ml}$ of $\mathrm{O}_{2}$ per minute in the second episode; $p<0.001$, Mann-Whitney's test). (Fig. 2D)

\section{Preconditioning effects on acute and chronic seizures}

To evaluate the impact of hypoxic preconditioning in acute and chronic seizures, we recorded animal behaviors in video and analyzed parameters of their ictal events during SE and the SRS period. HSE rats displayed higher latency to SE than SE animals (47.0 \pm 2.6 and $35.0 \pm 2.5$, respectively; $p=0.002$, MannWhitney's test; Fig. 3A). HSE animals also showed a trend to display a less severe ictal behavior as compared to SE rats $(3.8 \pm 0.1 ; 4.1 \pm 0.1 ; p=0.09$, Mann-Whitney's test; Fig. 3B).

Behavioral recordings during the chronic phase indicated that HSE group had no differences from SE group regarding number of animals without SRS (40\%, $4 / 10$ and $12.5 \%, 1 / 8$, respectively; $p>0.05$, Fisher's test), latency to SRS (17.5 \pm 7.38 vs. $11.14 \pm 3.55$; days; Mann-Whitney's test, $p=0.23$ ), SRS duration $(35.5 \pm 8.67$ vs. $45.14 \pm 13.86$; seconds; MannWhitney's test, $p=0.62)$, SRS frequency $(9.16 \pm 3.15$ vs. $19.28 \pm 8.86 ; p=0.33$, Student $t$-test), and SRS
A

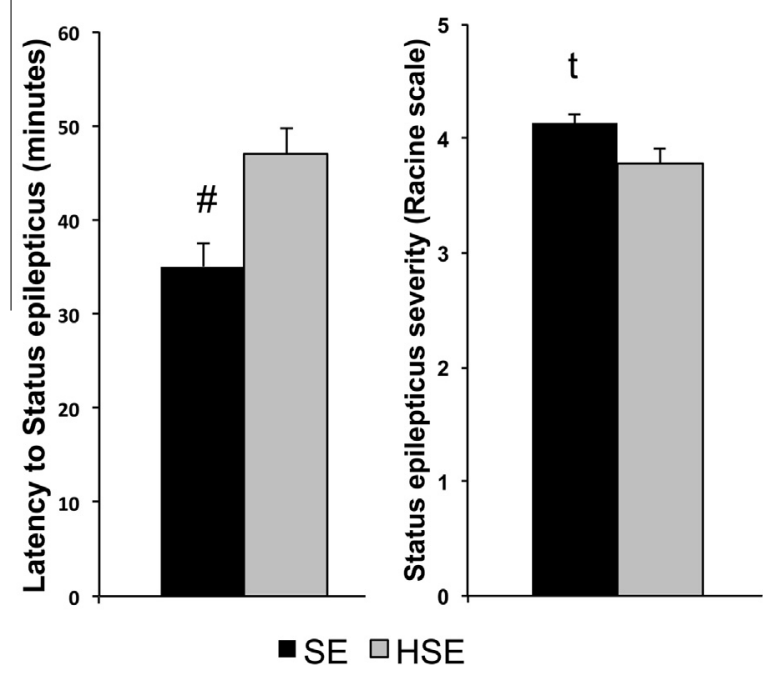

Fig. 3. Latency (A) and severity (B) of status epilepticus after lithiumpilocarpine administration in rats from status only (SE) and hypoxia + status (HSE). HSE group had higher latency to status epilepticus (A) and lower severity of status epilepticus (B) than SE group. The (\#) indicates statistical difference from HSE group, and the $(t)$ indicates trend towards difference from HSE group. severity (Racine score of $3.16 \pm 0.30-$ HSE vs. 3.42 \pm 0.42 - SE; $p=0.36$, Mann-Whitney's test).

\section{Hypoxic preconditioning effects on spatial memory}

Considering the time to complete the task, all groups performed similarly during the two first session blocks. However, HSE and SE had slower performances in the block $3(p=0.04, \mathrm{RM}$ ANOVA) and HSE in the block 5 ( $p=0,02$; RM ANOVA), when compared to the Control group (Fig. 4A). In the first block of the spatial memory test, HSE and control animals showed similar performances, exhibiting lower error rates when compared to SE animals (Fig. 4B). Statistical analysis showed differences in the number of errors between groups during the analyzed period $(p<0.001$, RM ANOVA), with no significant group-block interaction $(p=0.7)$. SE rats had more errors than HSE rats in the first three blocks of the experiment, and more errors than Control in all blocks ( $p \leqslant 0.002$; Fig. 4B).

\section{Neuronal loss and mossy fiber sprouting}

Neuroprotective effects of hypoxic preconditioning were evaluated by counting viable neurons in different hippocampal subfields of animals euthanized 1 or 60 days after SE. One day after the SE, HSE rats had a higher neuronal density in the hilus $(p<0.001$; ANOVA), CA3c $(p<0.001$; ANOVA $)$ and CA3b $(p=0.018$; ANOVA) when compared to SE group. SE group presented lower neuronal density in the hilus, CA3c, and CA3a ( $p<0.004$; ANOVA), when compared to $\mathrm{H}$ and $\mathrm{C}$, and in the CA1 $(p<0.001$; ANOVA), compared to $\mathrm{H}$ group. HSE rats had lower neuronal densities only in CA3c $(p<0.001$; ANOVA), compared to $\mathrm{H}$ group (Fig. $5 \mathrm{~A}$ ).

Sixty days after SE, HSE group had higher neuronal density in the hilus ( $p=0.02$ ANOVA) and CA3a ( $p=0.04$ ANOVA), compared to SE, and lower neuronal density in CA3a ( $p \leqslant 0.001$ ANOVA) and in CA1 $(p<0.05$, Kruskal-Wallis) than $\mathrm{H}$ group (Figs. 4 and 5). SE animals had lower neuronal density than the $\mathrm{H}$ and $\mathrm{C}$ in CA3a, CA2 ( $p<0.005$ ANOVA) and CA1 $(p<0.05$, Kruskal-Wallis; Fig. 5B and Fig. 6).

To investigate the growth and reorganization of axonal collaterals in the hippocampus following SE, we quantified mossy fiber sprouting in the DG using Neo-Timm staining at different time points after SE: 1 and 60 days. We observed an intense mossy fiber sprouting in SE animals 60 days after SE, while HSE had a milder sprouting (Fig. 7). The comparison of mossy fiber scores showed a higher frequency of scores 3 and 4 in SE animals, whereas HSE had a higher frequency of scores 1 and 2 (Fisher's exact test, $p=0.02$; Table 2). No mossy fiber sprouting was detected in $\mathrm{H}$ and $\mathrm{C}$ animals ( $p>0.05$, Kruskal-Wallis).

\section{DISCUSSION}

Although both a high oxygen situation (Gasier et al., 2015) and a major hypoxic event (Owens et al., 1997; Amato and Donati, 2000; Maiti et al., 2007) can cause sei- 

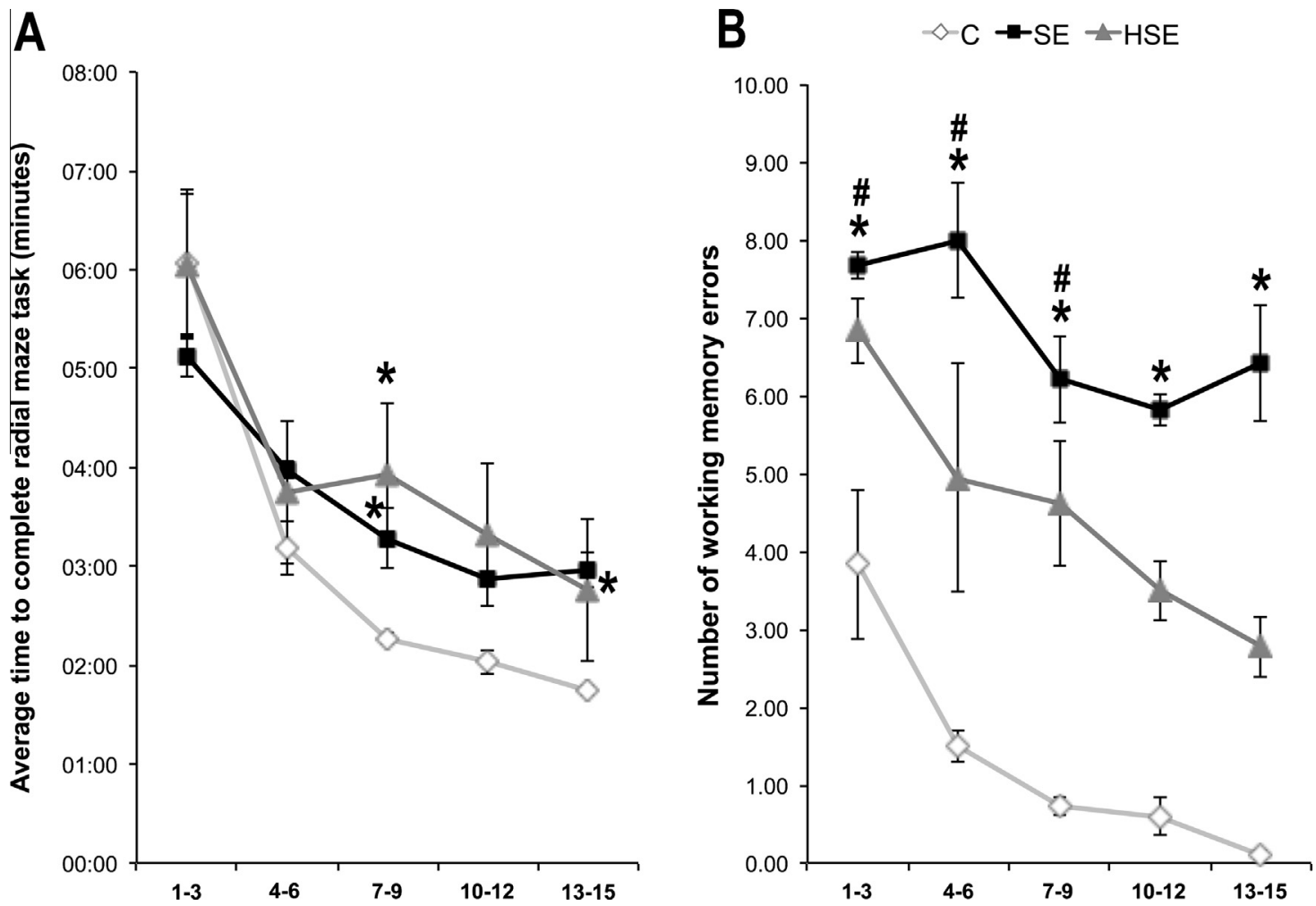

Fig. 4. Radial-maze performance time (A) and working memory errors (B) during the 15 days of the test (grouped in blocks of 3 days) for control (C), status only (SE), and hypoxia + status (HSE). Performances of HSE animals improved along training sessions. Compared to C, HSE spent more time to complete the task in the third and fifth blocks, and SE had slower performance in the third block (A). SE rats had worst performance in radial maze task than $\mathrm{C}$ group in all experimental blocks and also worst performance than HSE from the first to the third blocks (B). The $\left(^{*}\right)$ indicate differences compared from control group and (\#) differences from HSE group. Data are shown as the mean \pm SEM.

zures and promote epileptogenesis in rats and humans, a controlled, shorter hypoxic event can induce short and long-term neuroprotection against a later insult (Semenza, 2000; Kirino, 2002). Our main findings indicated that hypoxic preconditioning: (1) increased latency to SE; (2) improved performance in a spatial memory task; (3) reduced neuronal death in the hilus and CA3; and (4) reduced mossy fiber reorganization in the inner molecular layer of DG.

In the Pilo SE model, a previous electrically induced seizure or ischemic episode is known to increase SE latency (Heim et al., 1991; Andre et al., 2000; Andre et al., 2007). The hypoxic preconditioning paradigm used also increased the latency to SE, corroborating these findings. Hypoxic preconditioning showed a trend towards lower seizure severity during SE. Whereas some studies indicated lower SE severity following hypoxia (Pohle and Rauca, 1994; Rauca et al., 2000), studies with electroshock or amygdala electrical kindling priming showed no effect on SE severity (Andre et al., 2000). One possible mechanism that could explain the effect of hypoxia on SE is the activation of adenosine A3 receptors, depressing postsynaptic sensitivity to glutamate and decreasing glutamatergic cholinergic coupling (Dunwiddie et al., 1997).

The SRS that follow the epileptogenic period in TLE patients are also seen in rats submitted to Li-Pilo SE (Leite et al., 1990; Cavalheiro et al., 1991). Previous studies have shown that KA-induced short-term seizure and amygdala kindling priming does not influence the latency of SRS induced by Li-Pilo SE (Andre et al., 2000; Zhang et al., 2002). On the other hand, electroshock preconditioning significantly reduced the number of rats which developed SRS, compared to non-preconditioned Li-Pilo animals (Andre et al., 2000). However, the interictal abnormalities in all electroshock-preconditioned animals were similar to non-preconditioned animals (Andre et al., 2000). Furthermore, KA priming does not affect the frequency of SRS induced by Li-Pilo in the first eight weeks, but significantly reduces the frequency of severe SRS (stage 4-6 seizures) after the eighth week (Zhang et al., 2002). Our preconditioned group had no difference from non-preconditioned Li-Pilo animals regarding SRS duration, frequency, or severity. The dentate gate hypothesis (Lothman et al., 1992) offers an interesting mechanism to explain why the preconditioning failed to prevent SRS. According to this hypothesis, the intrinsic characteristics of the fascia dentata's granule cells, such as extensive inhibitory feedback/feedforward circuitry and hyperpolarized resting membrane potential (Krook-Magnuson et al., 2015), make this subfield crucial for preventing SRS. In the epileptic condition, there is a significant loss of granule cell GABAerginc input, as well as reorganization of granule cell axons from the hilus to the apical dendrites of granule cells (McNamara, 1994). In agreement with this hypothesis, optogenetic inhibition of granule cells prevents SRS (Krook-Magnuson et al., 2015). Thus, it is possible that, even though the priming reduced the severity of the $\mathrm{SE}$, it was not robust enough to prevent molecular and 
A

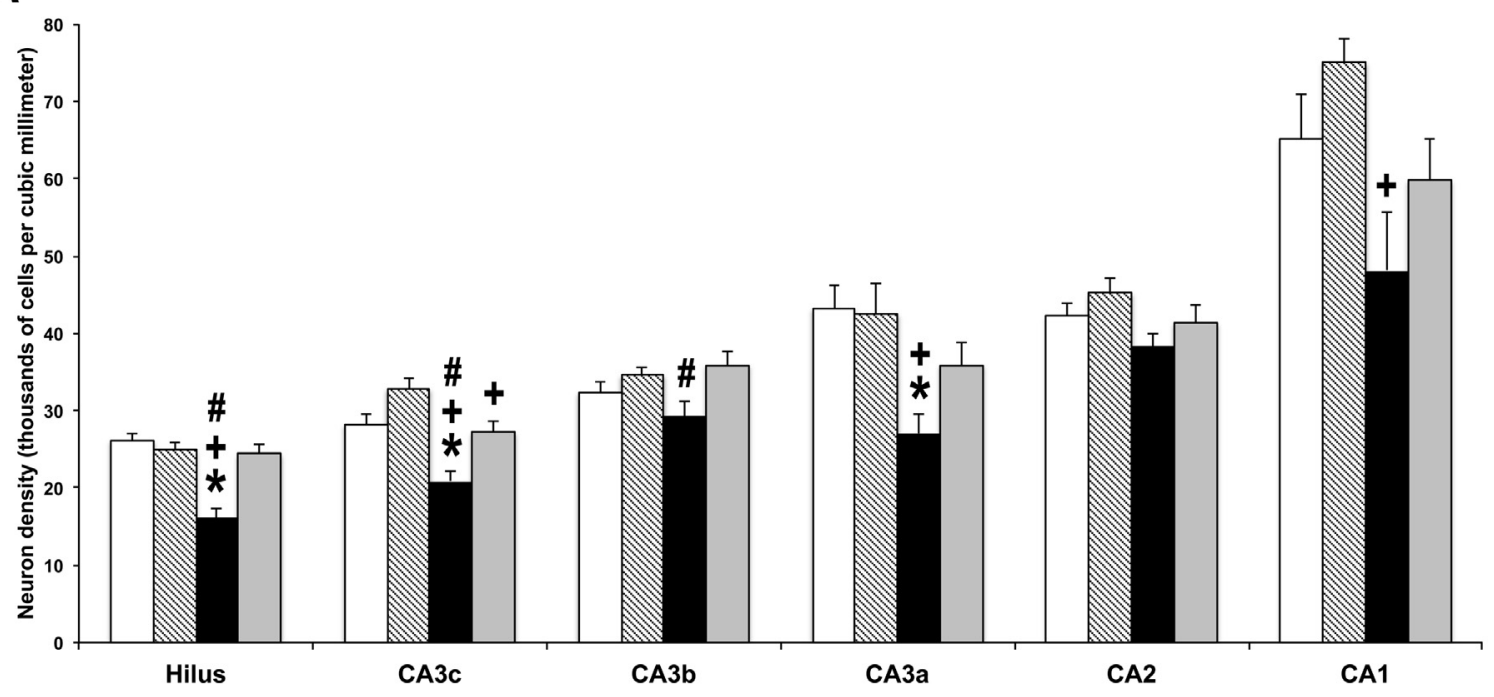

B

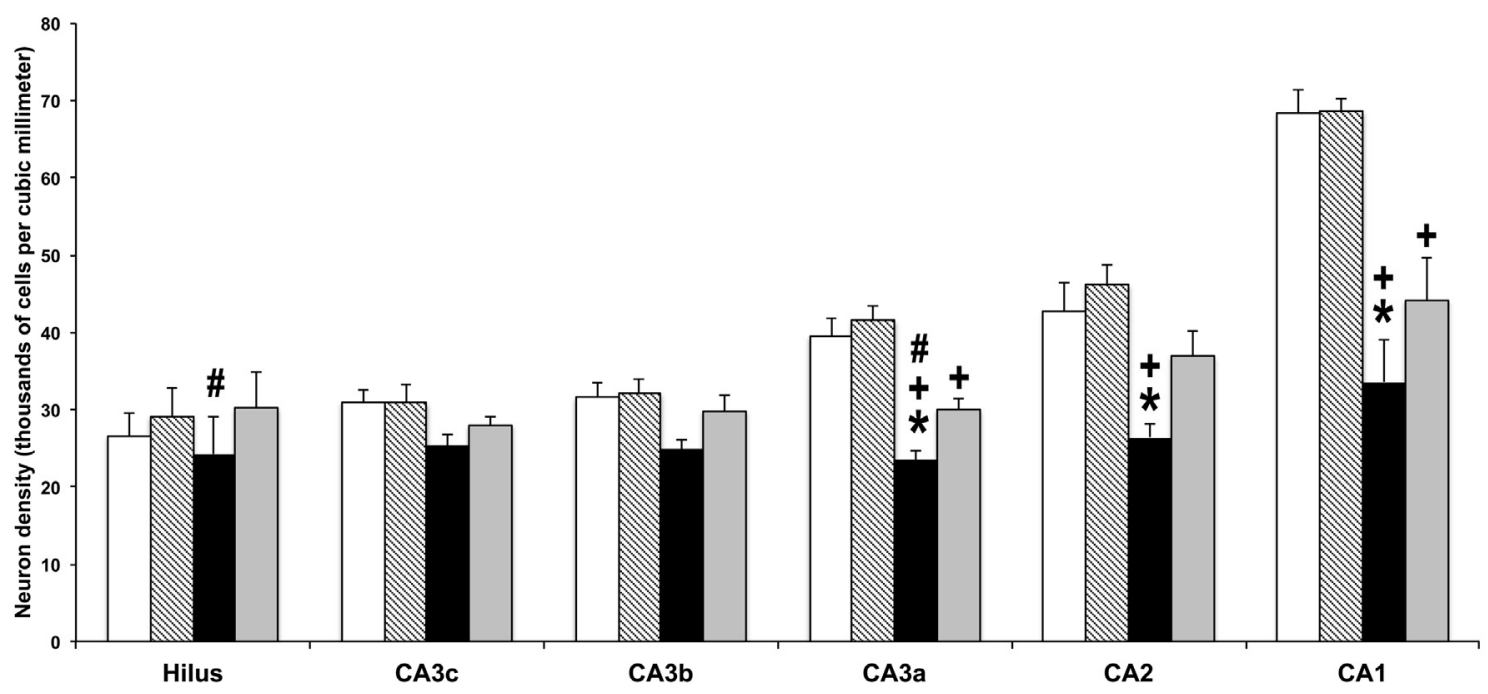

Fig. 5. Neuron density estimation from Nissl-stained hippocampal sections in control and experimental groups at one (A) and 60 (B) days after status epilepticus or saline administration. $\mathrm{C}=$ control; $\mathrm{H}=$ hypoxia only; $\mathrm{SE}=$ status epilepticus only; $\mathrm{HSE}=$ hypoxia preconditioning. $\mathrm{SE}$ had lower neuron density than all groups in the hilus and CA3C at one day and in CA3a at 60 days. SE had lower neuron density than $\mathrm{H}$ and $\mathrm{C}$ in CA3a at one day and CA2 and CA1 at 60 days. SE also had lower neuron density in CA3b at one day, compared to HSE group, and in CA1, compared to H group. HSE group had lower neuron density than $\mathrm{H}$ group only in CA3C at one day and CA3a and CA1 at 60 days. The $\left(^{*}\right)$ indicate difference from $\mathrm{C}$ group, $(+)$ indicates difference from $\mathrm{H}$ group, and $(\#)$ indicates difference from HSE group.

circuitry changes, such as mossy fiber sprouting, that leads to the emergence of the SRS. In fact, our HSE animals presented with mossy fiber sprouting.

Animals submitted to SE show neuropathological changes that reproduce those seen in TLE patients (Leite et al., 1990; Bertram, 2007; Thom, 2009). Since a previous study demonstrated that a short hypoxic event could protect neurons from a posterior, major hypoxia (Kirino, 2002), we aimed to evaluate the neuroprotective effect of hypoxia on neuron survival in the Li-Pilo SE model. In our study, preconditioned rats that exhibited SRS had significant neuronal protection when compared to SE animals in the acute and chronic periods. In KA or pentylenetetrazole-induced SE, a mild hypoxia is known to protect hilar, CA3, and CA1 neurons in the acute period (Pohle and Rauca, 1994; Emerson et al., 1999). Other preconditioning models also showed neuroprotection in the acute, epileptogenic and chronic period post-SE (Kelly and Mclntyre, 1994; Zhang et al., 2002). The neuroprotective effect of oxygen deprivation appears similar to that induced in animals tolerant to anoxia triggered during hibernation (Kirino, 2002). This moderate hypoxia situation induces adaptive responses that enhance neuronal survival. (Semenza, 2000). Moreover, a transient ischemic attack is known to protect against harmful stroke event in humans (Moncayo et al., 2000; Keep et al., 2010). Therefore, priming the brain with a mild cellular stress may unleash a widespread molecular 

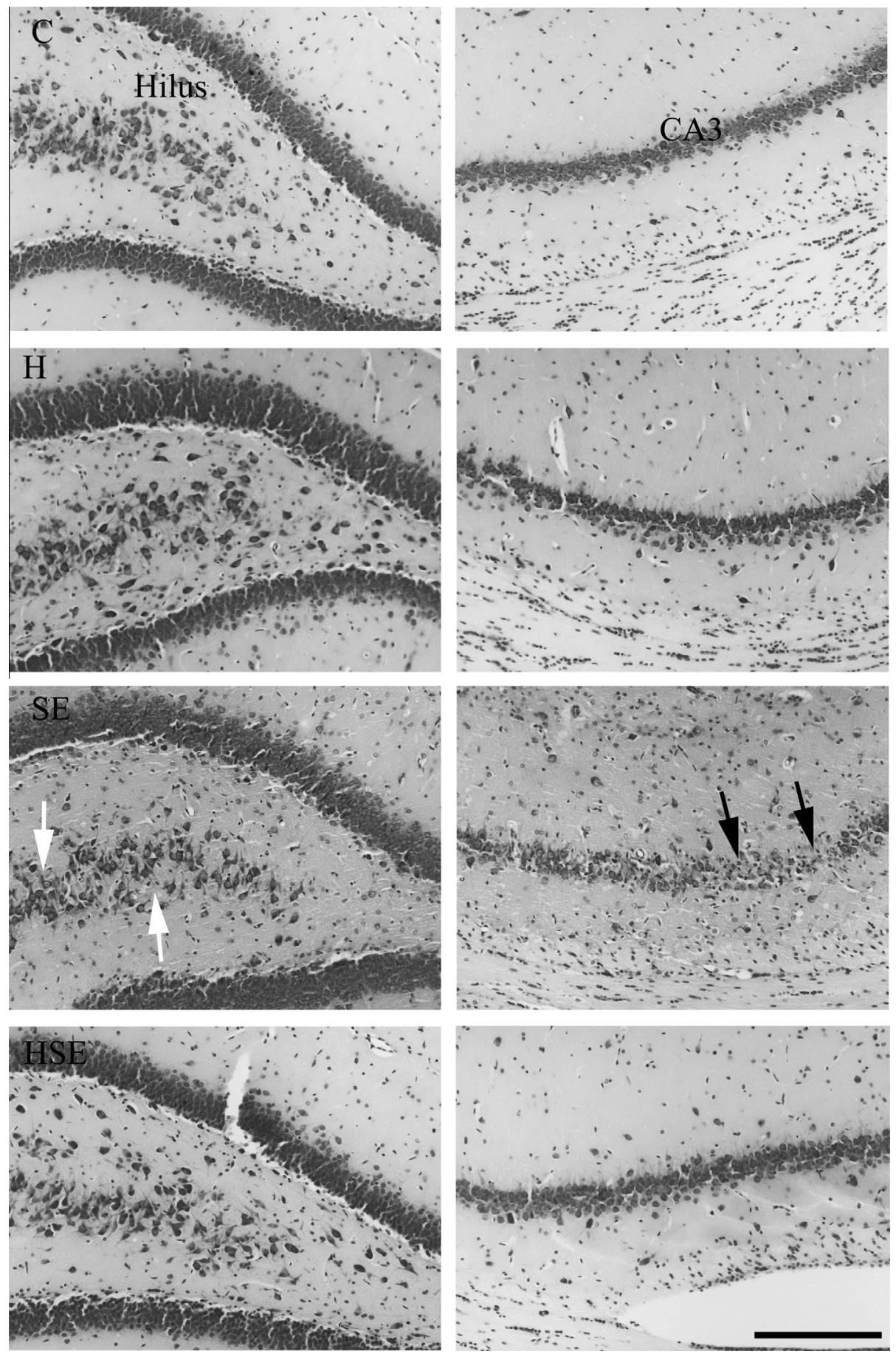

Fig. 6. Representative Nissl-stained hippocampal sections showing the hilus (left column) and CA3 (right column) subfields from animals 60 days after status epilepticus induction. SE rats had significant neuron loss in the hilus (indicated by white arrows), compared to HSE, and CA3a (indicated by black arrows) compared to C, H, and HSE animals. Bar in the bottom-right panel indicates $200 \mu \mathrm{m}$.

response capable of interfering with the mechanisms of neuronal loss, degeneration, and mossy fiber sprouting seen in MTLE. In fact, studies with hypoxia and seizure preconditioning provided evidence that the priming episode induces differential gene expression, with minimal overlap to the gene expression promoted by the same stimuli in injurious levels (Stenzel-Poore et al., 2003; Simon et al., 2007). Amongst the potential neuroprotective changes promoted by hypoxia priming are downregulation of ionotropic glutamate receptors and upregulation of heat-shock proteins, glial fibrillary acidic protein, superoxide dismutase, and adenosine (Emerson et al., 1999; Kirino, 2002; Stenzel-Poore et al., 2003). The time course of neuroprotection shown by different preconditioning paradigms suggests the recruitment of distinct endogenous mechanisms. More studies focusing on the molecular mechanisms associated with neuroprotection in hypoxic preconditioning would be necessary to 

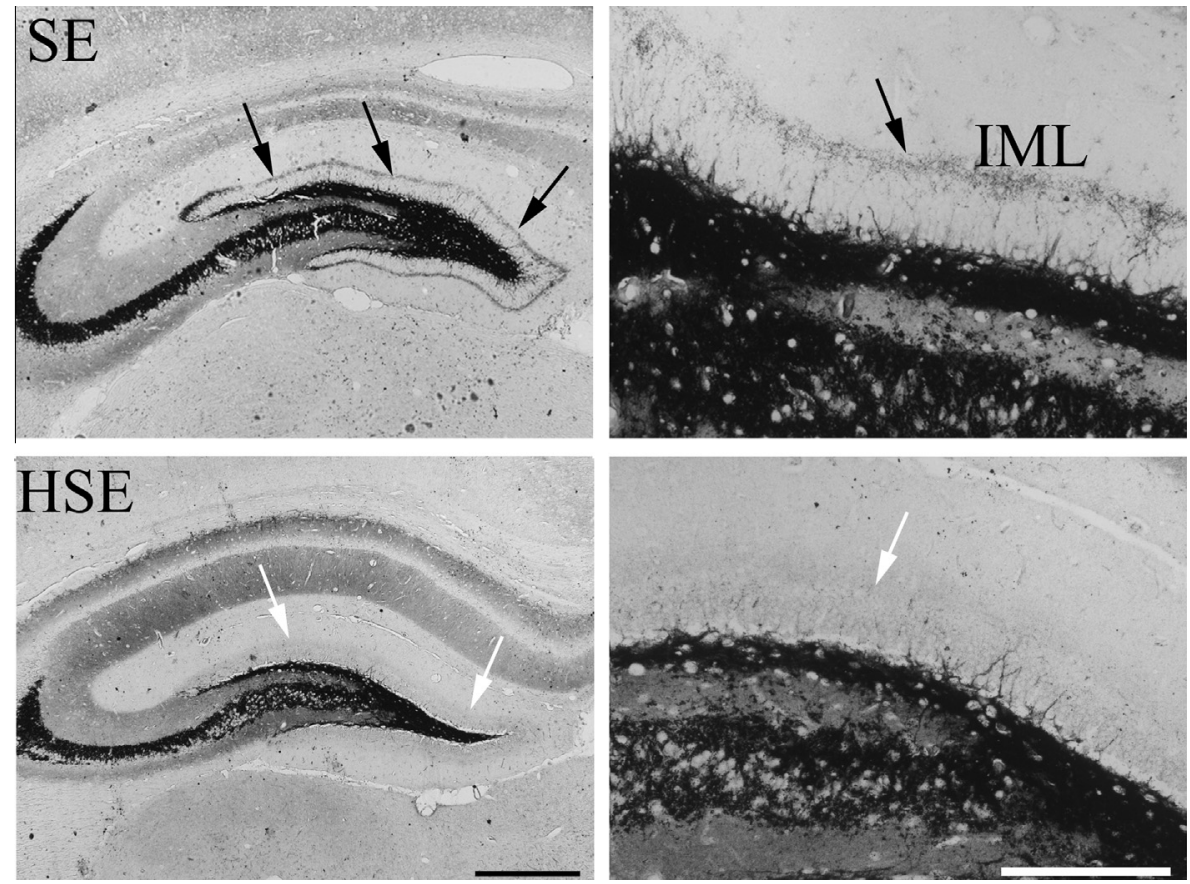

Fig. 7. Representative neo-Timm-stained hippocampal sections showing the dentate gyrus (DG) from SE and HSE animals 60 days after status epilepticus induction. Positive neo-Timm staining (gray granules, pointed by black arrows) is seen in the inner molecular layer of SE rats, whereas HSE animals have almost no positive staining (white arrows). Bar in HSE in the left panel indicates $500 \mu \mathrm{m}$ and in the right panel indicates $200 \mu \mathrm{m}$.

Table 2. Neo-Timm staining scores

\begin{tabular}{lll}
\hline Groups & Low score (\%) & High score $(\%)$ \\
\hline SE & $17^{*}$ & 83 \\
HSE & 86 & 14 \\
\hline
\end{tabular}

Intensity of neo-Timm staining in the hippocampal fascia dentata inner molecular layer of experimental animals arranged in low (0-1) and high (2-3) staining scores. Fisher's exact test, $(p=0.02)$ indicates that HSE animals had a greater percentage of animals with low Timm's scores that SE animals.

Percentage of animals per group.

translate the experimental results for clinical use in MTLE patients.

The synaptic reorganization of mossy fiber axons of granule cells in the molecular layers of the dentate gyrus is a common morphological alteration observed in the hippocampus of TLE patients (Sutula et al., 1989; Babb et al., 1991; Mathern et al., 1995b). According to some studies, this reorganization can contribute for the hippocampal hyperexcitability (Sutula et al., 1989; Covolan et al., 2000). In KA priming, animals submitted to two short KA seizures before KA-induced SE had no mossy fiber sprouting until 140 days after SE (Zhang et al., 2002). As in previous studies, we saw mossy fiber reorganization in the inner molecular layer of rats submitted to Li-Pilo SE. The preconditioning group had a milder mossy fiber sprouting 60 days after SE when compared to SE group. Since the HSE group had no significant neuron loss in the hilus and only a discrete loss in CA3, it was expected a milder, if any, mossy fiber sprouting.

The neuronal loss also has important implications for cognition and memory. Studies with TLE patients have shown that neuron loss in specific hippocampal subfields can promote differential memory loss (Coras et al., 2014; Rodrigues et al., 2015). Besides, SRS might cause progressive cognitive decline (Sutula et al., 1995). Li-Pilo SE is known to impair spatial memory (Detour et al., 2005). Spatial memory was also diminished in KA or pentylenetetrazole-induced SE models (Letty et al., 1995; Mortazavi et al., 2005). Our SE group was severely impaired in the spatial learning task, as shown by the time to reach learning criterion and number of memory errors. However, hypoxic preconditioned animals had fewer errors and spent less time to complete the memory task than SE group. Thus, we found that the exposure to hypoxic preconditioning attenuated the memory deficit induced by Li-Pilo SE.

\section{CONCLUSION}

Our data showed the cellular and behavioral protective effect of hypoxic preconditioning preceding a SE in acute and chronic epilepsy phases. We demonstrate that hypoxic preconditioning treatment reduced hippocampal neuron loss, axonal reorganization, and improve memory performance. Taken together our data indicates that hypoxic preconditioning increases neuron resistance to injury, protecting the neuronal population and cognition. However, this effect is not enough to prevent the changes that occur in the epileptogenic period that promote seizure recurrence. Thus, further studies are needed to investigate the molecular mechanisms involved in the long-term neuroprotection and recurrent seizure emergence, which could have clinical implications for epilepsy treatment. 


\section{DISCLOSURE}

Conceived and designed the experiments: O.Y.G.A., M.L. G., J.P.L. Performed the experiments: R.A.V.S., J.E.P.S., P.A.B., M.B., R.C.S. Analyzed the data: R.A.V.S., R.N.R. P., O.Y.G.A. Contributed reagents/materials/analysis tools: M.B., M.L.G., R.C.S., R.N.R.P., O.Y.G.A., J.P.L. Wrote the paper: RAVS, JEPS, OYGA, JPL.

None of the authors has any conflict of interest to disclose. All authors have read and approved the final draft.

\begin{abstract}
Acknowledgements-We would like to thank Antonio Renato Meirelles e Silva and Humberto Di Giusti for their excellent technical support and the contribution of our laboratory colleagues in valuable discussions and suggestions. Funding: This work was supported by the Fundacao de Amparo a Pesquisa do Estado de Sao Paulo [FAPESP, grant numbers 2005/56447-7 and 2010/51515-2] and Conselho Nacional de Desenvolvimento Cientifico e Tecnologico [CNPq, grant numbers 476250/2013-7 and 466995/2014-8]. The funding agencies had no role in the study design, data collection and analysis, decision to publish or preparation of the manuscript.
\end{abstract}

\section{REFERENCES}

Abercombrie M (1946) Estimation of nuclear population from microtome sections. Anat Rec 94:239-247.

Amato M, Donati F (2000) Update on perinatal hypoxic insult: mechanism, diagnosis and interventions. Eur J Paediatr Neurol 4:203-209.

Andre V, Dube C, Francois J, Leroy C, Rigoulot MA, Roch C, Namer IJ, Nehlig A (2007) Pathogenesis and pharmacology of epilepsy in the lithium-pilocarpine model. Epilepsia 48(Suppl. 5):41-47.

Andre V, Ferrandon A, Marescaux C, Nehlig A (2000) The lesional and epileptogenic consequences of lithium-pilocarpine-induced status epilepticus are affected by previous exposure to isolated seizures: effects of amygdala kindling and maximal electroshocks. Neuroscience 99:469-481.

Arthur-Farraj PJ, Latouche M, Wilton DK, Quintes S, Chabrol E, Banerjee A, Woodhoo A, Jenkins B, Rahman M, Turmaine M, Wicher GK, Mitter R, Greensmith L, Behrens A, Raivich G, Mirsky R, Jessen KR (2012) C-Jun reprograms Schwann cells of injured nerves to generate a repair cell essential for regeneration. Neuron 75:633-647.

Babb TL, Kupfer WR, Pretorius JK, Crandall PH, Levesque MF (1991) Synaptic reorganization by mossy fibers in human epileptic fascia dentata. Neuroscience 42:351-363.

Baquet ZC, Williams D, Brody J, Smeyne RJ (2009) A comparison of model-based (2D) and design-based (3D) stereological methods for estimating cell number in the substantia nigra pars compacta (SNpc) of the C57BL/6J mouse. Neuroscience 161:1082-1090.

Bassi M, Nakamura NB, Furuya WI, Colombari DS, Menani JV, do Carmo JM, da Silva AA, Hall JE, Colombari E (2015) Activation of the brain melanocortin system is required for leptin-induced modulation of chemorespiratory function. Acta Physiol 213:893-901.

Bateman LM, Li CS, Seyal M (2008) Ictal hypoxemia in localizationrelated epilepsy: analysis of incidence, severity and risk factors. Brain 131:3239-3245.

Ben-Ari Y, Cossart R (2000) Kainate, a double agent that generates seizures: two decades of progress. Trends Neurosci 23:580-587.

Berg AT, Berkovic SF, Brodie MJ, Buchhalter J, Cross JH, van Emde BoasW, Engel J, French J, Glauser TA, Mathern GW, Moshe SL, Nordli D, Plouin P, Scheffer IE (2010) Revised terminology and concepts for organization of seizures and epilepsies: report of the
ILAE Commission on Classification and Terminology, 2005-2009. Epilepsia 51:676-685.

Bertram E (2007) The relevance of kindling for human epilepsy. Epilepsia 48(Suppl. 2):65-74.

Boeck CR, Ganzella M, Lottermann A, Vendite D (2004) NMDA preconditioning protects against seizures and hippocampal neurotoxicity induced by quinolinic acid in mice. Epilepsia 45:745-750.

Bortolotto ZA, Heim C, Sieklucka M, Block F, Sontag KH, Cavalheiro EA (1991) Effects of bilateral clamping of carotid arteries on hippocampal kindling in rats. Physiol Behav 49:667-671.

Cavalheiro EA, Leite JP, Bortolotto ZA, Turski WA, Ikonomidou C, Turski $L$ (1991) Long-term effects of pilocarpine in rats: structural damage of the brain triggers kindling and spontaneous recurrent seizures. Epilepsia 32:778-782.

Chang AY, Wang CH, Chiu TH, Chi JW, Chen CF, Ho LT, Lin AM (2005) Hypoxic preconditioning attenuated in kainic acid-induced neurotoxicity in rat hippocampus. Exp Neurol 195:40-48.

Clifford DB, Olney JW, Maniotis A, Collins RC, Zorumski CF (1987) The functional anatomy and pathology of lithium-pilocarpine and high-dose pilocarpine seizures. Neuroscience 23:953-968.

Coras R, Pauli E, Li J, Schwarz M, Rossler K, Buchfelder M, Hamer H, Stefan H, Blumcke I (2014) Differential influence of hippocampal subfields to memory formation: insights from patients with temporal lobe epilepsy. Brain 137:1945-1957.

Covolan L, Ribeiro LT, Longo BM, Mello LE (2000) Cell damage and neurogenesis in the dentate granule cell layer of adult rats after pilocarpine- or kainate-induced status epilepticus. Hippocampus 10:169-180.

Curia G, Lucchi C, Vinet J, Gualtieri F, Marinelli C, Torsello A, Costantino L, Biagini G (2014) Pathophysiogenesis of mesial temporal lobe epilepsy: is prevention of damage antiepileptogenic? Curr Med Chem 21:663-688.

de Araujo HerculanoB, Vandresen-Filho S, Martins WC, Boeck CR, Tasca Cl (2011) NMDA preconditioning protects against quinolinic acid-induced seizures via PKA, PI3K and MAPK/ERK signaling pathways. Behav Brain Res 219:92-97.

Detour J, Schroeder H, Desor D, Nehlig A (2005) A 5-month period of epilepsy impairs spatial memory, decreases anxiety, but spares object recognition in the lithium-pilocarpine model in adult rats. Epilepsia 46:499-508.

Dunwiddie TV, Diao L, Kim HO, Jiang JL, Jacobson KA (1997) Activation of hippocampal adenosine $\mathrm{A} 3$ receptors produces a desensitization of $\mathrm{A} 1$ receptor-mediated responses in rat hippocampus. J Neurosci 17:607-614.

Emerson MR, Nelson SR, Samson FE, Pazdernik TL (1999) Hypoxia preconditioning attenuates brain edema associated with kainic acid-induced status epilepticus in rats. Brain Res 825:189-193.

Fabene PF, Merigo F, Galie M, Benati D, Bernardi P, Farace P, Nicolato E, Marzola P, Sbarbati A (2007) Pilocarpine-induced status epilepticus in rats involves ischemic and excitotoxic mechanisms. PLoS One 2:e1105.

Gasier HG, Demchenko IT, Allen BW, Piantadosi CA (2015) Effects of striatal nitric oxide production on regional cerebral blood flow and seizure development in rats exposed to extreme hyperoxia. $J$ Appl Physiol 119:1282-1288.

Gualtieri F, Marinelli C, Longo D, Pugnaghi M, Nichelli PF, Meletti S, Biagini G (2013) Hypoxia markers are expressed in interneurons exposed to recurrent seizures. NeuroMol Med 15:133-146.

Heim C, Bortolotto ZA, Cavalheiro EA, Sontag KH (1991) Transient occlusion of rat carotid arteries decreases susceptibility to pilocarpine seizures. Brain Res 544:253-259.

Jope RS, Morrisett RA, Snead OC (1986) Characterization of lithium potentiation of pilocarpine-induced status epilepticus in rats. Exp Neurol 91:471-480.

Kandratavicius L, Balista PA, Lopes-Aguiar C, Ruggiero RN, Umeoka EH, Garcia-Cairasco N, Bueno-Junior LS, Leite JP (2014a) Animal models of epilepsy: use and limitations. Neuropsychiatr Dis Treat 10:1693-1705.

Kandratavicius L, Hallak JE, Carlotti CG, Assirati Jr JA, Leite JP (2014b) Neurotrophin receptors expression in mesial temporal 
lobe epilepsy with and without psychiatric comorbidities and their relation with seizure type and surgical outcome. Acta Neuropathol Commun 2:81.

Kandratavicius L, Peixoto-Santos JE, Monteiro MR, Scandiuzzi RC, Carlotti Jr CG, Assirati Jr JA, Hallak JE, Leite JP (2015) Mesial temporal lobe epilepsy with psychiatric comorbidities: a place for differential neuroinflammatory interplay. J Neuroinflamm 12:38.

Kandratavicius L, Rosa-Neto P, Monteiro MR, Guiot MC, Assirati Jr JA, Carlotti Jr CG, Kobayashi E, Leite JP (2013) Distinct increased metabotropic glutamate receptor type 5 (mGluR5) in temporal lobe epilepsy with and without hippocampal sclerosis. Hippocampus 23:1212-1230.

Keep RF, Wang MM, Xiang J, Hua Y, Xi G (2010) Is there a place for cerebral preconditioning in the clinic? Transl Stroke Res 1:4-18.

Kelly ME, McIntyre DC (1994) Hippocampal kindling protects several structures from the neuronal damage resulting from kainic acidinduced status epilepticus. Brain Res 634:245-256.

Kirino T (2002) Ischemic tolerance. J Cereb Blood Flow Metab 22:1283-1296.

Kitagawa K, Matsumoto M, Tagaya M, Hata R, Ueda H, Niinobe M, Handa N, Fukunaga R, Kimura K, Mikoshiba K, et al. (1990) 'Ischemic tolerance' phenomenon found in the brain. Brain Res 528:21-24.

Krook-Magnuson E, Armstrong C, Bui A, Lew S, Oijala M, Soltesz I (2015) In vivo evaluation of the dentate gate theory in epilepsy. J Physiol 593:2379-2388.

Lee DA, Bedont JL, Pak T, Wang H, Song J, Miranda-Angulo A, Takiar V, Charubhumi V, Balordi F, Takebayashi H, Aja S, Ford E, Fishell G, Blackshaw S (2012) Tanycytes of the hypothalamic median eminence form a diet-responsive neurogenic niche. Nat Neurosci 15:700-702.

Leite JP, Bortolotto ZA, Cavalheiro EA (1990) Spontaneous recurrent seizures in rats: an experimental model of partial epilepsy. Neurosci Biobehav Rev 14:511-517.

Leite JP, Garcia-Cairasco N, Cavalheiro EA (2002) New insights from the use of pilocarpine and kainate models. Epilepsy Res 50:93-103.

Letty S, Lerner-Natoli M, Rondouin G (1995) Differential impairments of spatial memory and social behavior in two models of limbic epilepsy. Epilepsia 36:973-982.

Lorente de Nó R (1934) Studies on structure of the cerebral cortex. II. Continuation of the study of the ammoniac study. J Psychol Neurol 45:113-117.

Lothman EW, Stringer JL, Bertram EH (1992) The dentate gyrus as a control point for seizures in the hippocampus and beyond. Epilepsy Res Suppl 7:301-313.

Lowenstein DH (1996) Recent advances related to basic mechanisms of epileptogenesis. Epilepsy Res Suppl 11:45-60.

Lucchi C, Vinet J, Meletti S, Biagini G (2015) Ischemic-hypoxic mechanisms leading to hippocampal dysfunction as a consequence of status epilepticus. Epilepsy Behav 49:47-54.

Maiti P, Singh SB, Muthuraju S, Veleri S, Ilavazhagan G (2007) Hypobaric hypoxia damages the hippocampal pyramidal neurons in the rat brain. Brain Res 1175:1-9.

Malan A (1973) Ventilation measured by body plethysmography in hibernating mammals and in poikilotherms. Respir Physiol 17:32-44.

Mathern GW, Babb TL, Leite JP, Pretorius K, Yeoman KM, Kuhlman PA (1996) The pathogenic and progressive features of chronic human hippocampal epilepsy. Epilepsy Res 26:151-161.

Mathern GW, Babb TL, Vickrey BG, Melendez M, Pretorius JK (1995a) The clinical-pathogenic mechanisms of hippocampal neuron loss and surgical outcomes in temporal lobe epilepsy. Brain 118(Pt 1):105-118.

Mathern GW, Pretorius JK, Babb TL (1995b) Quantified patterns of mossy fiber sprouting and neuron densities in hippocampal and lesional seizures. J Neurosurg 82:211-219.

McNamara JO (1994) Cellular and molecular basis of epilepsy. J Neurosci 14:3413-3425.

Mello LE, Cavalheiro EA, Tan AM, Kupfer WR, Pretorius JK, Babb TL, Finch DM (1993) Circuit mechanisms of seizures in the pilocarpine model of chronic epilepsy: cell loss and mossy fiber sprouting. Epilepsia 34:985-995.

Moncayo J, de Freitas GR, Bogousslavsky J, Altieri M, van Melle G (2000) Do transient ischemic attacks have a neuroprotective effect? Neurology 54:2089-2094.

Mortazavi F, Ericson M, Story D, Hulce VD, Dunbar GL (2005) Spatial learning deficits and emotional impairments in pentylenetetrazolekindled rats. Epilepsy Behav 7:629-638.

Najm IM, Hadam J, Ckakraverty D, Mikuni N, Penrod C, Sopa C, Markarian G, Luders HO, Babb T, Baudry M (1998) A short episode of seizure activity protects from status epilepticusinduced neuronal damage in rat brain. Brain Res 810:72-75.

Olton DSaSRJ (1976) Remembrance of places passed: spatial memory in rats. J Exp Psychol Anim Behav Process 2:97-116.

Owens Jr J, Robbins CA, Wenzel HJ, Schwartzkroin PA (1997) Acute and chronic effects of hypoxia on the developing hippocampus. Ann Neurol 41:187-199.

Paxinos GaWC (1986) The rat brain stereotaxic coordinates. New York: Academic Press.

Peixoto-Santos JE, Velasco TR, Galvis-Alonso OY, Araujo D, Kandratavicius L, Assirati JA, Carlotti CG, Scandiuzzi RC, Santos AC, Leite JP (2015) Temporal lobe epilepsy patients with severe hippocampal neuron loss but normal hippocampal volume: Extracellular matrix molecules are important for the maintenance of hippocampal volume. Epilepsia 56:1562-1570.

Pohle W, Rauca C (1994) Hypoxia protects against the neurotoxicity of kainic acid. Brain Res 644:297-304.

Racine RJ (1972) Modification of seizure activity by electrical stimulation. II. Motor seizure. Electroencephalogr Clin Neurophysiol 32:281-294.

Rao MS, Hattiangady B, Reddy DS, Shetty AK (2006) Hippocampal neurodegeneration, spontaneous seizures, and mossy fiber sprouting in the F344 rat model of temporal lobe epilepsy. J Neurosci Res 83:1088-1105.

Rauca C, Zerbe R, Jantze H, Krug M (2000) The importance of free hydroxyl radicals to hypoxia preconditioning. Brain Res 868:147-149.

Rodrigues GR, Kandratavicius L, Peixoto-Santos JE, Monteiro MR, Gargaro AC, Geraldi Cde V, Velasco TR, Leite JP (2015) Increased frequency of hippocampal sclerosis ILAE type 2 in patients with mesial temporal lobe epilepsy with normal episodic memory. Brain 138:e359.

Rubaj A, Gustaw K, Zgodzinski W, Kleinrok Z, Sieklucka-Dziuba M (2000) The role of opioid receptors in hypoxic preconditioning against seizures in brain. Pharmacol Biochem Behav 67: 65-70.

Sasahira M, Lowry T, Simon RP, Greenberg DA (1995) Epileptic tolerance: prior seizures protect against seizure-induced neuronal injury. Neurosci Lett 185:95-98.

Schmued LC, Albertson C, Slikker Jr W (1997) Fluoro-Jade: a novel fluorochrome for the sensitive and reliable histochemical localization of neuronal degeneration. Brain Res 751(1):37-46.

Semenza GL (2000) HIF-1: mediator of physiological and pathophysiological responses to hypoxia. J Appl Physiol 88:1474-1480.

Simon R, Henshall D, Stoehr S, Meller R (2007) Endogenous mechanisms of neuroprotection. Epilepsia 48(Suppl. 8):72-73.

Stenzel-Poore MP, Stevens SL, Xiong Z, Lessov NS, Harrington CA, Mori M, Meller R, Rosenzweig HL, Tobar E, Shaw TE, Chu X, Simon RP (2003) Effect of ischaemic preconditioning on genomic response to cerebral ischaemia: similarity to neuroprotective strategies in hibernation and hypoxia-tolerant states. Lancet 362:1028-1037.

Sutula T, Cascino G, Cavazos J, Parada I, Ramirez L (1989) Mossy fiber synaptic reorganization in the epileptic human temporal lobe. Ann Neurol 26:321-330.

Sutula T, Lauersdorf S, Lynch M, Jurgella C, Woodard A (1995) Deficits in radial arm maze performance in kindled rats: evidence for long-lasting memory dysfunction induced by repeated brief seizures. J Neurosci 15:8295-8301. 
Tauck DL, Nadler JV (1985) Evidence of functional mossy fiber sprouting in hippocampal formation of kainic acid-treated rats. $J$ Neurosci 5:1016-1022.

Thom M (2009) Hippocampal sclerosis: progress since Sommer. Brain Pathol 19:565-572.

Touzani K, Puthanveettil SV, Kandel ER (2007) Consolidation of learning strategies during spatial working memory task requires protein synthesis in the prefrontal cortex. Proc Natl Acad Sci U S A 104:5632-5637.

Tramontin AD, Smith GT, Breuner CW, Brenowitz EA (1998) Seasonal plasticity and sexual dimorphism in the avian song control system: stereological measurement of neuron density and number. J. Comp. Neurol. 396:186-192.
Turski WA, Cavalheiro EA, Schwarz M, Czuczwar SJ, Kleinrok Z, Turski $L$ (1983) Limbic seizures produced by pilocarpine in rats: behavioural, electroencephalographic and neuropathological study. Behav Brain Res 9:315-335.

Wasterlain CG, Fujikawa DG, Penix L, Sankar R (1993) Pathophysiological mechanisms of brain damage from status epilepticus. Epilepsia 34(Suppl. 1):S37-53.

Xue Y, Xie N, Cao L, Zhao X, Jiang H, Chi Z (2011) Diazoxide preconditioning against seizure-induced oxidative injury is via the PI3K/Akt pathway in epileptic rat. Neurosci Lett 495:130-134.

Zhang X, Cui SS, Wallace AE, Hannesson DK, Schmued LC, Saucier DM, Honer WG, Corcoran ME (2002) Relations between brain pathology and temporal lobe epilepsy. J Neurosci 22:6052-6061.

(Accepted 24 June 2016)

(Available online 29 June 2016) 